\title{
Same Same but Different: the Relationship Between Organizational Reputation and Organizational Public Value
}

\author{
Timo Meynhardt ${ }^{1,2} \cdot$ Pepe Strathoff ${ }^{2} \cdot$ Andreas Fröhlich $^{1} \cdot$ Steven A. Brieger ${ }^{2,3}$
}

(c) Reputation Institute and Springer Nature Limited 2019

\begin{abstract}
Organizational public value and organizational reputation are different concepts stemming from independent research traditions. Nevertheless, the constructs share several similarities, which make a systematic comparison and investigation of their relationship a promising and necessary endeavor. In this paper, we compare the two constructs along seven dimensions, with special attention to the micro-level of individual psychology. Several similarities regarding strategic relevance, locus of control, measurement unit, process dynamics, and axiological nature exist. As we will see, the constructs differ significantly with respect to the basis of evaluation and their dominant logic. We draw on a recent micro-foundation of public value to elaborate on these differences and develop propositions about how the constructs are related. Public value applies a holistic basis of evaluation covering all basic values and collective frames of reference, while reputation is more adaptive. Moreover, public value follows a logic of contribution (to a collective), while reputation follows a logic of recognition (by a collective). The two constructs should not be taken as similar or used interchangeably. However, both fields can benefit from a joint theoretical basis and micro-foundation, as well as from connected research programs. Practitioners should consider both constructs in connection.
\end{abstract}

Keywords Organizational reputation $\cdot$ Public value $\cdot$ Construct comparison $\cdot$ Axiology $\cdot$ Micro-foundation

But the matter [the Volkswagen diesel emission scandal] is not just about jobs, market share or corporate and bureaucratic reputations. The scandal captures Germany at a moment when it has been trying to hold on to values it always saw as defining, but that have become increasingly difficult to maintain as it becomes drawn into the messy problems of Europe and the world.

-The New York Times, September 23, 2015.

Timo Meynhardt

timo.meynhardt@hhl.de

Pepe Strathoff

pepe.strathoff@gmail.com

Andreas Fröhlich

aut.froehlich.andreas@gmail.com

Steven A. Brieger

s.a.brieger@sussex.ac.uk

\section{Introduction}

The above quote from a New York Times article discusses the consequences of the Volkswagen diesel emission scandal for Germany. It indicates that part of the damage done by the scandal relates to values in society that are touched, shaken, and perhaps even destroyed. The article is aptly titled: A Car Scandal Shoves Berlin Off High Ground. It makes clear that the scandal touches a sensitive spot, because at stake here are public values such as efficiency, rectitude, and ecology which Germans see as self-defining, even worthy of advocating to others, and of which they are proud. The article is revealing as it focuses not only on the damage to the firm's

1 Dr. Arend Oetker Chair of Business Psychology and Leadership, HHL Leipzig Graduate School of Management, Leipzig, Germany

2 Center for Leadership and Values in Society, University of St. Gallen, St. Gallen, Switzerland

3 University of Sussex Business School, University of Sussex, Brighton, United Kingdom 
or the country's reputation, as many other comments did, but also articulates consequences for the German society as a whole, which include a weakening of those public values which are part of peoples' experience and perception of reality. In this sense, the article points to a construct which holistically describes how VW is valuable for Germany, from people's own subjective perspective, different from its reputation: It refers to VW's public value.

The public value construct, which is originally rooted in public administration research (Moore 1995) has recently been expanded to become applicable to any (public and private) context (Meynhardt 2009, 2015; Meynhardt and Fröhlich 2019). It aims to holistically describe the value of an organization for a social collective and has also been referred to as an organization's contribution to the common good (Meynhardt 2016). Especially in light of the latter definition, differences between public value and reputation seem intuitively clear: One would hardly equate an organization's contribution to the common good with its reputation. In view of these definitional differences, the compelling example above, and the long independent research traditions of the two constructs, one may easily conclude that reputation and public value are fundamentally different constructs.

Nevertheless, when examining recent conceptual works on public value and reputation more closely (Meynhardt 2009, 2015; Meynhardt and Fröhlich 2019; Walker 2010), it appears that the constructs have more in common than one would expect at first sight. Public value is described as the result of shared "evaluations" (Meynhardt 2009, p. 200), while reputation refers to "aggregate perceptions" (Walker 2010, p. 370) of an organization. Public value results from evaluations against a "basis of evaluation" (Meynhardt 2009, p. 200), while reputation is the result of a comparison "against some standard" (Walker 2010, p. 370). The "Public" in Public Value, refers to "any group" of humans, be it inside or outside an organization (Meynhardt and Fröhlich 2019), while reputation similarly can involve all "internal and external stakeholders" (Walker 2010, p. 367). Obviously, as one would expect, both research streams use different vocabulary. However, it is striking that these words seem to refer to similar underlying concepts and processes. If so, what are the exact differences of the two constructs and how are they related?

We believe that only a systematic comparison of reputation and public value can shed light on the similarities, differences, and relationships of the two constructs. There seems to exist an interesting research gap that is highly relevant for theory building in both fields, as to our knowledge, there has been no such connection of these adjacent research streams so far. The most immediate benefit of such a comparison would be a contribution to sharpening the terminology, definitions, and theoretical basis of both constructs. Both public value research (Bryson et al. 2014) and reputation research (Podnar and Golob 2017) are still struggling to find common ground in this regard and could need more clarity on the dimensionalities and dynamics of the constructs (Kraatz and Love 2006; Lange et al. 2011; Bryson et al. 2014).

Beyond that, given that both constructs are rooted in subjective perceptions, a thorough comparison of public value and reputation would have to address the level of individual psychology. This could foster the development, advancement, and application of micro-foundations of public value and reputation. We understand micro-foundations as groundings of (traditionally macro-level) conceptions in individual (micro-level) psychology and behavior, which encompass how people interpret events, process information, derive meaning, and as such enact the macro-level. Such microfoundations have been widely called for in organizational, management, and strategy literature in general (Barney and Felin 2013) and in particular for concepts related to societal value creation (Aguinis and Glavas 2012).

Meynhardt $(2009,2015)$ and Meynhardt and Fröhlich (2019) developed and made use of a "micro-foundation of value" in their conceptual works, which helped to significantly sharpen the definition of the public value construct, but also to expand research into individual-level and contextindependent applications of the concept. Given the similarities of public value and reputation, we believe that this micro-foundation of value can be applied to the reputation construct as well and can help to define and compare public value and reputation more closely.

Beyond that, applying such a micro-foundation would root the reputation construct more strongly in individual psychology and complement institutional and organizational level research. The field of organizational reputation needs more work on the underlying cognitive processes. Reputation has been described as "affective evaluation" (Cable and Graham 2000, p. 929; Rhee and Valdez 2009, p. 146). However, reputation research still has to "get inside the heads of those whose perceptions determine reputation" (Barnett and Pollock 2012, p. 13). The public value literature has developed more explicit micro-foundations, which could prove suitable for the reputation construct as well.

Besides the contributions described above, new ways of research could unfold enabling the various fields to complement and benefit from each other. More holistic theories about the value and/or reputation of organizations can be developed, providing the basis for new hypotheses, research designs, and refined empirical methods with higher validity and construct clarity. Also, practitioners dealing with one or both constructs could gain much from clarity on their delineation and how they are related. This would facilitate the operationalization, assessment, and management of reputation and public value.

The purpose of this paper, therefore, is to analyze the constructs organizational reputation and organizational public 
value for their similarities and differences and to propose pertinent aspects of their relationship, with special attention to the constructs' micro-foundations. We start by providing an overview on both constructs, including the microfoundation of value underlying the public value construct, before systematically comparing public value and reputation along seven dimensions. We show that the constructs are similar regarding their strategic relevance, locus of control, axiological nature, measurement unit, and process dynamics. However, the constructs differ significantly with respect to the basis of evaluation and their dominant logic. Further, we illustrate the differences by a thought experiment related to the VW diesel scandal example at the beginning. Based on this, we come up with propositions that point to the relationships between the two constructs. Finally, we discuss how research and practice should consider the similarities and differences in distinct, yet closely linked programs, and we give our conclusions.

\section{Organizational Public Value and Organizational Reputation}

\section{Public Value}

Public value research is an emerging field (Bryson et al. 2014, 2015), which has its roots in the public management research domain (e.g., Moore 1995; Meynhardt 2009; Meynhardt and Bartholomes 2011; Kearney and Meynhardt 2016; Meynhardt et al. 2017). Over the past decade, the concept has increasingly found its way into management literature of the private sector (e.g., Meynhardt 2015; Strathoff 2015; Meynhardt and Gomez 2016; Meynhardt et al. 2016; Meynhardt 2019; Meynhardt and Bäro 2019; Meynhardt and Fröhlich 2019). Public value rankings are widely published, thus getting considerable media attention (https://www.gemei nwohl.ch/en/atlas; https://www.gemeinwohlatlas.de/en/atlas ), and a number of firms have conducted public value studies, ${ }^{1}$ e.g., Swiss insurance Mobiliar, German Stock Exchange operator Deutsche Börse AG (Meynhardt and von Müller 2013), and the soccer club FC Bayern Munich (Meynhardt et al. 2017).

The notion of public value provides a novel way of understanding the value organizations create for social collectives (Moore 1995; Meynhardt 2009, 2015). It builds on a perspective that every organization creates not only economic value, but also values in a number of other dimensions, by contributing to producing and reproducing social realities. The concept actually shifts the ground in terms of value creation by systematically reinforcing an outside-in perspective

\footnotetext{
${ }^{1}$ For an overview, see Meynhardt (2015, pp. 158-159).
}

for assessing a firm's value to society. Public value rests on Drucker's idea that every organization, be it a firm, a public administration, or an NGO, influences how well society functions, and thus always performs a social function (Drucker 1992). Initially, in public sector management research, the concept was supposed to help public managers in their strategic decision-making (Moore 1995). According to Moore, father of the public value concept, "managers must satisfy some kinds of desires and operate in accord with some kinds of perceptions" (Moore 1995, p. 52). Thus, early on, Moore emphasized the relevance of need satisfaction and perception for creating public value.

Consequently, one of the central advancements of public value during the last decade has been a comprehensive psychological micro-foundation of the construct (Meynhardt 2009, 2015; Meynhardt and Fröhlich 2019; Meynhardt and Bartholomes 2011). Based on an in-depth philosophical and psychological analysis of the concept, Meynhardt (2009, 2015), and later Meynhardt and Fröhlich (2019), developed a theory of public value that would broaden the definition of the construct and open up new ways of theory building and empirical research (Meynhardt and Bartholomes 2011). The concept was soon adopted by practitioners and gained widespread attention in management in Europe.

The central underlying assumption of the micro-foundation of public value is that, following a humanistic world view, humans are the final arbiters of value creation. One can thus speak of actual value creation only if it is the result of subjective evaluation by humans (Meynhardt and Fröhlich 2019). Organizations constantly interact with many people, be it their (internal or external) stakeholders, larger communities, or society; in public value theory all of these social collectives are referred to as "publics." Given their widespread influence on these publics, organizations are constantly evaluated with respect to their impact on them, by the individuals constituting the publics. The outcome of such evaluation is the public value of the organization. In other words, organizations create public value as they shape and co-create individuals' experience of their social contexts and realities. In its original definition, public value refers to "[a]ny impact on shared experience about the quality of the relationship between the individual and [a public]" (Meynhardt 2009, p. 212).

In a functional sense, organizations "cannot but influence public values" (Meynhardt 2009, p. 193), because by their very existence they shape individuals' perception of the social collective. Accordingly, public value is of central importance both as feedback "drawn from" the social collectives one interacts with, and as an order parameter, or a "regulative idea" (Meynhardt 2009, p. 204), that guides individuals, organizations, other social units, and society as a whole in making valuable decisions, actions, and consequently, contributions (Meynhardt 
and Fröhlich 2019). As such, public value can be seen as a new way of considering notions such as the common good, public interest, or bonum commune in a managerial way, that is, a way that complements a legal perspective and the operationalization of philosophical ideas. Importantly, while deliberations like this have been motivations for developing the construct, the construct as such is primarily descriptive, i.e., non-normative.

The micro-foundation of (public) value consists of several more detailed elements (see Meynhardt 2009, 2015; Meynhardt and Fröhlich 2019), which we will refer to in the later comparison as they provide a basis for assessing important commonalities and differences with the reputation construct. These elements rest with Meynhardt's reference to formal axiology, which is the field of philosophy concerned with the study of values (Meynhardt 2009). We will distinguish the Axiological Nature of Evaluation, the Basis of Evaluation (with a special role of "the public"), and the Object of Evaluation.

Before closing this short introduction, we want to briefly highlight how public value relates to the concept of Corporate Social Responsibility. The association can at first seem natural, as both concern the relationship between organizations and social collectives (Schwartz and Carroll 2008). Although this paper does not give a detailed comparison of the two concepts, existing literature (Meynhardt and Fröhlich 2019; Meynhardt and Gomez 2016; Carroll and Shabana 2010; Garriga and Melé 2004; Schwartz and Carroll 2008; Aguinis and Glavas 2012; Strathoff 2015) indicates that, even though overlaps exist, the concepts differ on important dimensions. Most importantly, while public value relates to a specific, but integrative theory of value, the term CSR is associated with "competing, complementary and overlapping concepts" (Carroll and Shabana 2010, p. 2), with some underlying themes such as value, balance, and accountability (Schwartz and Carroll 2008).

Since both concepts have an integrative character, each may be described through the lens of the other. From the perspective of CSR research, public value can be described as a micro-founded, integrative, and non-normative theory about the value of organizations for social collectives. In this sense, it represents a deeper and broader, yet descriptive notion of CSR. Public value adds to CSR, as it provides an overdue psychological micro-foundation (Aguinis and Glavas 2012) to complement organizational and institutional level research. Public value broadens CSR by not merely relating to specific values (e.g., economic or moral), social contexts (e.g., minorities), or proposed hierarchies (Carroll 1991; Meynhardt and Gomez 2016), but also allowing for a holistic, non-hierarchical consideration of a human basis of evaluation. In this sense, it explicitly takes the culturally contingent nature of corporate responsibility (Campbell 2007) and its reflection in subjective evaluations of stakeholders and the general public into account (Meynhardt and Gomez 2016). Public value theory is also explicitly nonnormative. Many CSR concepts, by contrast, are rooted in normative premises around responsibility and accountability (Schwartz and Carroll 2008).

From the perspective of public value theory, public value provides a micro-foundation of value that allows for describing, comparing, challenging, and advancing any other existing or potential value concept. As such, it can allocate and integrate not only CSR, but any other conceivable value concept, such as shareholder value, stakeholder value, shared value, etc. (Gomez and Meynhardt 2014). Within Public Value theory, CSR becomes one among many concepts that can be associated with a single field or a group of fields. It can be challenged with respect to its ability to represent actual value creation for a group of human beings (Meynhardt and Fröhlich 2019). It follows that no matter which perspective one takes, public value and CSR are related, yet quite different as regard their depth, breadth, and premises.

\section{Organizational Reputation}

As has been outlined above, public value rests on very specific theoretical assumptions. Yet, adjacent research streams, and especially the one on organizational reputation, exhibit commonalities and patterns that also apply to public value. Therefore, in this section, we describe the organizational reputation construct, in order to provide a basis for subsequently understanding how public value is related to the concept of organizational reputation.

Organizational (or corporate) reputation refers to a relatively established field of research. Nevertheless, researchers still struggle to find common ground regarding a theoretical basis, as well as definitions of the construct and its relationships (Podnar and Golob 2017). As a matter of fact, Lange et al. (2011) warn that despite its apparent intuitive meaning and attractiveness, the concept of organizational reputation is actually quite complex.

Even so, comprehensive literature reviews and conceptual work in the field (Lange et al. 2011; Walker 2010; Podnar and Golob 2017; Barnett et al. 2006; Chun 2005; Fombrun and van Riel 1997; Fombrun 2012) point to definitions and common themes that enable identification of major commonalities and differences with respect to the public value construct.

A synthesizing definition of organizational reputation has been provided by Walker (2010), who expanded Fombrun's (1996) famous original definition after systematically reviewing the corporate reputation literature, as follows:

A relatively stable, issue specific aggregate perceptual representation of a company's past actions and future 
prospects compared against some standard (Walker 2010, p. 370).

Along with this definition, Walker (2010) identified five defining aspects of reputation, of which the initial three had already been pointed out by Fombrun (1996). First, organizational reputation is by nature subjective, as it is based on perceptions. Second, it relates to an aggregate of the perceptions of stakeholders of an organization. Third, it has an evaluative nature indicated by the phrase "compared against some standard." Fourth, organizational reputation can be positive or negative, which again emphasizes the evaluative aspect. Finally, the fifth characteristic refers to the fact that reputation is "relatively stable." This relative stability is considered of major importance in distinguishing between organizational reputation and the concept of organizational image (Walker 2010; Podnar and Golob 2017; Barnett et al. 2006). Reputation focuses on a holistic time frame, considering past actions and future prospects of the organization, while the organizational image relates more to current perceptions of the organization.

With respect to the first two characteristics, Walker (2010) points to two important matters. First, there is the issue-specific character of reputation. Depending on whether it refers to reputation for profitability, social responsibility, or other issues, the evaluation of individual subjects can differ considerably, and an aggregation can be problematic. Second, reputation can be quite different for different stakeholder groups of the organization, with similar implications for aggregation.

In what Podnar and Golob (2017) identified as the latest comprehensive review of reputation definitions, Lange et al. (2011) do not attempt a refined synthesis of definitions. However, they do point to three important dimensions of the construct: First, they highlight what they call the "being known" dimension, which refers to how familiar people generally are with the organization, i.e., to how well known an organization is, irrespective of evaluative judgments. For example, Shamsies (2003, p. 199) described organizational reputation as "the level of awareness that the firm has been able to develop for itself." Yet, other authors do not limit reputation to familiarity; rather, they include it as one dimension in their multidimensional understanding of organizational reputation (Rindova et al. 2005). Others argue that reputation and prominence are actually distinct constructs. For instance, Boyd et al. (2010, p. 6) find that "The distinction between prominence and reputation is that prominence refers to the degree to which an organization is visible and well known, whereas reputation involves an assessment of being good, bad, or somewhere in between." Yet other authors conceptualize familiarity not as a dimension, but as an important antecedent to organizational reputation (Brooks et al. 2003; Turban et al. 2001; Zajonc 1968).
Besides the "being known" dimension, Lange et al. (2011) distinguish two evaluative dimensions called "being known for something" and "generalized favorability." As opposed to the "being known" notion, these dimensions of organizational reputation explicitly entail an observer's evaluative judgements. "being known for something" focusses on organizations' reputation for very specific characteristics (Fischer and Reuber 2007), such as the quality of its products (Rindova et al. 2005). As this understanding of organizational reputation focusses on certain components of an organization that are relevant to particular stakeholder groups, it has been called the "componential perspective on organizational reputation" (Fischer and Reuber 2007, p. 57). Love and Kraatz $(2009$, pp. 317, 318) articulate this perspective on reputation as being focused on an organization's "technical efficacy" in delivering tangible outputs that are valued by evaluating audiences, as it helps them fulfill material needs. Accordingly, organizations are seen as "a means to audiences' parochial ends." This view relates to the issue and stakeholder specific part of Walker's (2010) definition presented above.

"Generalized favorability," in contrast, dissolves the notion of a specific reputation. Lange et al. (2011) define it as "an overall, generalized assessment of the organization's favorability." This understanding of reputation includes valuations of an organization by perceivers that take multiple attributes of the organization into account, and do not limit their judgements to an organization's performance in delivering to their parochial interest (Fischer and Reuber 2007). Authors that subscribe to this view of organizational reputation build on Fombrun's classic (1996, p. 72) definition of reputation as "a perceptual representation of a company's past actions and future prospects that describes the firm's overall appeal to its key constituents when compared to other leading rivals." We will revisit these features when now comparing reputation with the public value construct.

\section{Comparing Public Value and Organizational Reputation}

The above introductions of public value and reputation already suggest certain commonalities and differences between the constructs. The aim of this section is to comprehensively disclose and describe these commonalities and differences. Table 1 in Appendix gives an overview of the commonalities and differences of organizational public value and organizational reputation and the dimensions on which we compare the two constructs. As one will see, on a macro-level the constructs share several similarities, while when considering their micro-foundation, both similarities and differences become apparent. 


\section{Commonalities}

\section{Strategic Relevance}

We understand a construct as strategically relevant to organizations, when it can have a significant impact on the organization's short- or long-term performance and survival. Case study research has shown that public value potential is associated with growth opportunities (Meynhardt et al. 2015), and that public value risks over time translate into financial risks. Interestingly, a portfolio analysis has shown that firms with a higher public value outperform firms with a lower public value on the stock market (Berndt et al. 2015; Bilolo 2018). For public sector organizations, creating public value can even be seen as their raison d'être (Moore 1995) and if they are not seen to do so, their very existence is endangered (Meynhardt and Bartholomes 2011). Clearly, having a high public value has strategic relevance for organizations. In this regard, organizational reputation is no different. Reputation has proven to be a valuable asset for firms, as it reduces stakeholder uncertainty (Benjamin and Podolny 1999) and enables firms to charge price premiums (Shapiro 1983), which lead to increased financial performance (Roberts and Dowling 2002). Interestingly, empirical research has shown that the reputation damage caused by the Volkswagen Emissions Scandal has not only hurt Volkswagen but the German car industry as a whole leading to a strategically relevant loss of about \$3.7 billion of revenue in the US market (Bachmann 2017).

Therefore, we note that both public value and organizational reputation are strategically highly relevant assets for organizations.

\section{Locus of Control}

Locus of control is a term stemming from personality psychology that describes individuals' psychological disposition to attribute certain events in their life to external factors, thus believing that they have less control over their fate (Rotter 1954, 1966). The notion of organizational reputation often implies that organizations are anthropomorphized (Davies et al. 2001; Dowling 2001), i.e., they are viewed as coherent and purposive entities (Love and Kraatz 2009) with certain character traits such as reliability or trustworthiness (Fombrun 1996). We suggest giving this anthropomorphism another twist by framing the phenomenon of separating ownership and control of public value/organizational reputation as an instance of external locus of control. Given the strategic importance of public value and organizational reputation as "social approval assets" (Pfarrer et al. 2010, p. 1131), it is striking that both cannot be controlled by organizations. Whereas other strategically relevant assets such as financial means, patents, a skilled workforce, and other production factors are legally owned by (or in a contractual relationship with) organizations and can hence be controlled, high public value or a favorable reputation could be similarly important-as the preceding paragraph indicates-but cannot be controlled by the organization. This is evident, despite a certain understanding of ownership being attributed, as when we talk about "Nestlé's public value" or "BMW's reputation." Lange et al. (2011) point out that even though reputation is objectively held by an organization, it is subjectively created through cognitions and evaluations of third parties. So, we can state that when it comes to both public value and organizational reputation, an organization's locus of control is clearly external. Still, we should bear in mind that even though organizations cannot control their public value or reputation, mostly they can at least influence it. Both constructs are not subjectivist constructs which can be limited to arbitrary individual sentiments; rather, they are relational in the sense that value is co-produced by an evaluator and an evaluated object (the organization). As organizations have control about most of their actions and communications, they can influence features of the evaluated object (i.e., themselves), as well as the subject's perception of reality.

\section{Measurement Unit/Baseline}

With measurement unit/baseline, we refer to the standard by which the two constructs are quantified. When referring to both public value and organizational reputation, we tend to make statements such as "Organization A has high public value" or "The reputation of firm A is higher than the reputation of firm B." Clearly, we think about the constructs as being measured on some form of an ordinal scale, which allows comparisons of organizations which have more or less public value or organizational reputation. At the same time, statements such as "Organization $\mathrm{X}$ has a public value of five" or "Organization Y's reputation is 100 " make no sense, as there is no measurement unit associated with either construct and there is no zero-point on both scales. What we can do, however, is to compare organizations as is frequently done in public value (www.gemeinwohl.ch/en/atlas, http:// www.gemeinwohlatlas.de/en/atlas) and organizational reputation rankings (http://www.reputationinstitute.com/resea rch/Global-RepTrak-100). This approach to measuring and comparing corporate reputations is in line with Fombrun and Shanley's (1990) understanding of reputation as the result of a competition between firms to maximize their social status. By signaling to managers how successful they are in this competition, reputational rankings become a significant form of normative control (Fombrun and Shanley 1990). More recent definitions, however, generalize this comparative nature, requiring reputation just to have "some standard" as a basis for comparison (Walker 2010). Public value theory 
is similarly open concerning the measurement unit or the baseline (Meynhardt 2009).

\section{Process Dynamics}

The criterion of process dynamics refers to the processes of public value and organizational reputation emerging from individual evaluations, as well as to the stability and change of both constructs over time. Both constructs refer to aggregations of individual perceptions, thus to a certain link between the micro and macro levels. In that, both constructs offer some explanations of how aggregation leads to intersubjective realities and results, which in turn influence individual realities (Lange et al. 2011; Meynhardt 2009, 2015; Meynhardt et al. 2016). While both research streams still leave defining how such aggregations should be made open to empirical research designs, the micro-foundation of public value (Meynhardt 2009, 2015; Meynhardt and Fröhlich 2019) offers theoretical foundations that point to the critical design choices in such a process.

The underlying process dynamics of public value are synergetic. In this sense, public value is a systemic property (an order parameter), emerging from interaction and micro-macro links of individual evaluations. Seeing public value as an emergent phenomenon entails that it is qualitatively differently expressed ("gestalt") at the macro-level, to be more than, while still contingent on, individual evaluations (Meynhardt et al. 2016). In turn, public value, as a systemic order parameter influences or even determines the structure and content of individual evaluations-termed enslavement. ${ }^{2}$ Accordingly, the stability of public value over time depends on the strength of the order parameter and the extent to which new developments can (de-)stabilize the system (Ebeling and Feistel 1994; Haken 1977, 1984; Meynhardt et al. 2016). Regarding organizational reputation, its dynamic nature and stability have been identified as important features of the construct. However, the field deserves more research attention (Lange et al. 2011; Kraatz and Love 2006). Kraatz and Love (2006, p. 344) identified a "need to study reputation dynamically, and the specific need to examine how it is affected by various corporate actions." They provide some guidelines for such studies and discuss how the issue can be addressed in terms of methodology and multi-theory approaches in the reputation field. Particularly, the idea that reputation entails some form of expectation about an organization's future behavior (Fombrun 1996; Walker 2010) based on its past conduct, underlines the construct's dynamic nature. The underlying micro-foundation of public value could offer pointers towards a more systematic,

\footnotetext{
${ }^{2}$ For a detailed account, see Meynhardt et al. (2016) as well as
} Meynhardt and Fröhlich (2019). theory-driven conceptualization of organizational reputation dynamics.

\section{Axiological Nature}

In axiology, which is the branch of philosophy dealing with values, there is an ongoing debate about the nature of values (e.g., Rescher 1969), in particular whether they are rather objective or subjective. In this debate, Public value theory emphasizes the role of humans as the final arbiters of value creation. Building on psychology and value philosophy (Heyde 1926; Iwin 1975), value is defined as the result of the psychological evaluation of an object by a subject against a basis of evaluation. Value thus describes the quality of the subject-object relationship and public value is a relational concept, representing a middle ground between pure "subjectivist" and pure "objectivist" positions. Similarly, organizational reputation is the result of how a public evaluates a firm's activities. According to Fombrun and Shanley (1990, p. 234) "[p]ublics construct reputations." Hence, both constructs are relational in their basic axiology as they only come into being when an organization (object) is judged by a public (subject). This critical similarity provides the basis for comparing public value and reputation more closely on the level of individual psychology and for applying the micro-foundation of value to both constructs.

Proposition 1: Organizational public value and organizational reputation are both of strategic relevance to organizations, while at the same time beyond their direct control. The constructs are structurally similar, as they share a relational axiology, have predominantly relative evaluative character, and show similar process dynamics.

Proposition 2: Given the similarities of organizational public value and organizational reputation, theoretical and practical considerations for one construct can be transferred to the other, and vice versa. They can have similar antecedents and consequences, and be antecedent and/or consequent to one another. Moreover, similar methods can be applied for empirical assessment.

\section{Differences}

\section{Basis of Evaluation}

Having established that both public value and organizational reputation emerge through perceivers' judgements of organizations, a logical next question is what these judgements are based on and how individuals, consciously or unconsciously, form them. We believe that the difference between reputation and public value on this dimension can best be 
answered on the psychological level. We will draw on the micro-foundation of value developed by Meynhardt (2009, 2015) and Meynhardt and Fröhlich (2019) to explain the concept of a basis of evaluation and how public value and reputation relate to it.

Subjective evaluation is based on emotional-motivational forces that initiate an evaluation in a subject's mind. The basis of evaluation is the sum of all these forces that are active during an evaluation. An object is valued by, or has a certain value for a subject, if it impacts on such forces (Meynhardt and Fröhlich 2019).

Meynhardt $(2009,2015)$ and Meynhardt and Fröhlich (2019) build on theories on basic human needs (Epstein 1989, 2003), social cognition (Fiske and Taylor 1991; Fiske 1995; Schutz 1974; Schutz and Luckmann 1973), and human development (Kegan 1982, 1995; Kohlberg 1984) to arrive at an analytical structure for the basis of evaluation, called the (public) value matrix. The matrix, as illustrated in Fig. 1 in Appendix, has two dimensions, namely basic values that describe how value is created and personal frames of reference that describe for whom value is created from a subject's perspective.

Basic values correspond to the basic needs of individuals as the most fundamental of all emotional-motivational forces (Meynhardt 2009). All forces will ultimately relate to one or more of our basic needs, thus basic values are proposed to represent a "common ground" or a "quasi-ontological" basis (Meynhardt and Gomez 2016, p. 11). Meynhardt and Fröhlich (2019) propose that emotional-motivational forces not only relate to basic values, but also to one or more personal frames of reference. This is because human beings are social beings and, regardless of the developmental stage they are on, they are constantly influencing and being influenced by other people. Hence human beings very often, if not always, consider their conceptualizations of others, both consciously and unconsciously in their evaluations, and in construing their own realities. In other words, "for whom" value is created, forms a fundamental second dimension of the basis of evaluation.

Importantly, while there is a finite number of basic values, the numbers of frames of reference that play a role in evaluations are potentially infinite. Meynhardt and Fröhlich (2019) distinguish the most important conceptualizations as the self, the private surroundings, the professional surroundings, the local community, and society as a whole. However, conceivably, any more (or less) granular social entity could be a personal frame of reference.

The two dimensions of how and for whom value is created can then be analytically combined to illustrate the value categories of the (public) value matrix as an analytical structure for a general (i.e., construct-independent and context-independent) basis of evaluation. Any evaluation of an object, and as such the entire construction of a subject's reality, can be described by this matrix. Humans can differ according to their emphasis and awareness of these categories, and for individuals this can also vary depending on time and circumstances. One can also debate the exact content of both dimensions. However, if one accepts basic needs and personal frames of reference as a basis of evaluation, any value concept can be described, defined, and ultimately challenged against this basis, considering "how" and "for whom" they represent a true, i.e., psychologically real value creation.

Therefore, we believe that the (public) value matrix offers a suitable framework for comparing public value and reputation with regard to their basis' of evaluation. As regard reputation, Walker's (2010, p. 369) question on "reputation for what and according to whom" resembles the questions about how and for whom value is truly created. As such, issue and stakeholder specificity can be associated with the dimensions of the (public) value matrix and the differentiation of the "being known for" and "generalized favorability" dimensions can be put into a simple perspective.

We argue that an (issue- or stakeholder-)specific evaluation focuses on particular aspects of "how" and "for whom" something is valuable. ${ }^{3}$ In this sense, reputation covers specific value categories presented in the (public) value matrix. One could map any (issue- or stakeholder-) specific reputation construct on the basic value dimension (e.g., "reputation for profitability") or the frame of reference dimension (e.g., "reputation as perceived by shareholders"), or any combination thereof (e.g., "reputation for social responsibility as perceived by employees"). Generalized favorability, on the other hand, does not require any specification; either it explicitly demands a holistic evaluation by a subject, or leaves it open for a subject to choose its own basis of evaluation, consciously or unconsciously.

This means that the basis of evaluation of the reputation construct is not narrowly defined, but used adaptively in different conceptual and empirical contexts. It can be specific, representing the "being known for" dimension, or it can be more generalized, representing the "generalized favorability" dimension (Lange et al. 2011). This adaptive basis of evaluation concerns both dimensions of the (public) value matrix. Regarding basic values, reputation can refer to one or more specific basic values, or to one or more specific emotional-motivational forces relating to one or more basic values as the basis of evaluation. Therefore, with respect to basic values, the basis is either holistic or specific_-depending on the definition. Similarly, as it regard

\footnotetext{
${ }^{3}$ Lange et al. (2011) note that besides specific issues and stakeholders, specificity could also refer to specific contexts and process, i.e., components of the organization as the object. We elaborate on that at a later stage.
} 
frames of reference, definitions of reputation can vary as to whether they refer to a specific set of stakeholders (in this sense, frames of reference), or a more generalized aggregate thereof, such as society. Importantly, however, while reputation per definition refers to evaluation by a social collective, it does not necessarily require the consideration of this collective from the individual perspective.

The public value construct, on the other hand, is far less adaptive with respect to the basis of evaluation. As it aims at a holistic evaluation of an organization, per definition it requires some consideration of all basic values and all frames of reference. Although individuals can differ regarding the emphasis and awareness of categories in the (public) value matrix (Meynhardt and Fröhlich 2019), the conceptual definition of the construct demands a degree of consideration of all of them.

The requirement for being considered public value is not which public exactly is considered, but that at least one public frame of reference is involved. The defining aspect of public value is thus that it always involves evaluation from a system perspective. This means that, whenever an individual evaluates an object with reference to a public social unit, such as its family, a local community, or society as a whole, one can speak of public value from a subject's perspective. The definition of public value is also open with respect to how many public frames of reference are involved in evaluation. What is more, given its subjective nature, "objective" public value creation can only be achieved through a collectively (and as such intersubjectively) shared experience of the individuals constituting the public.

To conclude, while the organizational reputation construct has an adaptive basis of evaluation that is either holistic ("generalized favorability") or specific ("being known for") with respect to both basic values and frames of reference, the basis of public value evaluations is explicitly holistic. Importantly, due to the adaptive nature of reputation, one may choose to define a certain reputation construct that represents the same holistic basis of evaluation as public value constructs. Such an overlapping definition would represent what one might call a "reputation for public value." This leads us to Proposition 3.

Proposition 3: Reputation and public value differ with regard to their basis of evaluation. Reputation refers to subjective evaluations of an object against a basis of evaluation that can be adapted to be more or less holistic regarding the inclusion of basic values and frames of reference. Public value refers to subjective evaluations of an object against a basis of evaluation that explicitly covers all basic values and at least one frame of reference related to a social collective. Both on the individual and on an aggregated level, reputation and public value will be more distinct, the more the basis of evaluation of the two constructs differ.

\section{Dominant Logic}

Finally, we compare what we call the two constructs' dominant logic of evaluation, which describes how an organization is valued by and/or with reference to a collective. This is an important distinction rooted in the subjective nature of the object of evaluation. It is intuitively trivial, but conceptually complex, and thus perhaps responsible for some uncertainty around the distinctions between reputation and public value.

In a subjectivist worldview, there is no object as such; there can only be a certain association of perceptions in a subject's mind that can be summarized in a single mental representation, term, or image, called an "object." This can be any concrete or abstract, living or non-living element of our experienced reality, such as an apple, a tool, a process, a structure, an idea, a feeling, a cause, a consequence, a person, or an organization. In the act of evaluation, the subject takes a position towards, or associates a quality with the object, and as a result, the object's value arises (Meynhardt and Fröhlich 2019). In principal, both public value and reputation can be determined for any object; of course, the focus of "Organizational Public Value" and "Organizational Reputation" is the organization.

Especially for complex objects such as organizations, it is critical to highlight the implications of the subjective nature of objects in defining public value and reputation. A given organization, such as VW, can represent very different objects for different subjects. This means that the object that an individual subject evaluates can be different to the object that other individuals or a collective recognize. This is critical for the following considerations.

If one takes the lens of an individual subject, public value and reputation appear to be fundamentally different. As we have seen, an individual considering the public value of an organization performs evaluations with reference to a public, but these evaluations are primarily about the object as recognized by the individual, not by the public. The individual will focus predominantly on what other people experience because of the organization, but what other people recognize, or directly associate with an organization, plays a lesser role. In other words, the object of evaluation is the organization as perceived and conceptualized by the individual, and the evaluation as such is performed with respect to certain public frames of reference. Less technically, but perhaps more intuitively, one could argue that public value follows a logic of contribution in the sense that it describes the contribution the organization makes to the experienced reality of a collective social entity. It is about how an organization impacts collective experience. In this sense, public value follows Drucker's (1973) logic of contribution or value creation towards a common good (Meynhardt 2008).

This is fundamentally different to the reputation construct. Lange et al. (2011, p. 164) conclude that the being 
known dimension of the reputation construct relates to "shared perceptual representations." In this sense, reputation of an organization per definition refers to how an object represents itself to, or is recognized by, a collective. This means that what others recognize is inherent part of the definition of reputation. In other words: reputation, even from an individual perspective, is inherently linked to collective perceptions. An individual considering a certain kind of reputation for a social collective takes the perspective of the social collective both with respect to the conceptualization of the organization, as well as in evaluating this conceptualization. It is not about how a collective experiences its reality because of the organization, but how they experience the organization as such. In that, one could argue that reputation follows a logic of recognition of the organization by a social collective, i.e., it relies on what others recognize or associate with the concept of the organization.

This is an important difference between the two constructs which shows that, despite the similarities described above, they ultimately analyze different phenomena. Public value follows a logic of contribution to a collective, whereas reputation follows a logic of recognition by a collective.

Importantly, it is not clear what this distinction implies on a collective level, i.e., when considering public value and reputation as an aggregate of individual evaluations. Here, the difference between what an object represents to an individual vs the collective could become blurred as, with increasing "aggregation," the individuals enact, and in doing so, become the collective. Up to now, we have compared each construct's dominant logic from an individual perspective only. However, both research streams attach importance to aggregations of subjective evaluations, to arrive at intersubjective results and hence we shall consider this more closely.

As mentioned, theories on both constructs are vague as to how exactly an aggregation or emergence of the collective is achieved. This theoretical vagueness regarding the two constructs most likely causes some confusion: Technically speaking, if one aggregates individual perceptions, they become collective, or intersubjective, perceptions. However, following a synergetic viewpoint, one should not view "aggregation" merely as a sum of individual evaluations; rather, one should regard the common and overlapping aspects of the quality of a relationship involving a social entity, as its embodiment. In that, individual differentiations between own perceptions and the perceptions of others can become blurred in the same way as the differentiation between contribution and recognition can.

On an aggregate level, any contribution to the collective must somehow be recognized by the collective, and vice versa, any recognition by the collective constitutes a contribution to the collective. Consequently, as long as we have no clear theory or practical instructions about aggregations, there will always be some confusion regarding what an aggregated construct actually represents. Nevertheless, even on an aggregate level, the basis of evaluation remains a strong differentiating factor between public value and reputation. This leads us to Proposition 4.

Proposition 4: Reputation and public value differ with regard to their dominant logic, which is rooted in the subjective nature of the object of evaluation. Reputation focuses on a logic of recognition by a collective, while public value focuses on a logic of contribution to a collective. From the perspective of an individual subject, this distinction is clear and leads to different evaluation results for each construct, as the actual object of evaluation is different in each case. When aggregating individual perspectives to become a collective, or an intersubjective perspective, the distinction becomes blurred. Further investigation is required to define processes and results of such aggregations.

\section{A Thought Experiment}

In the introduction, we appealed to intuition when encouraging readers to "consider how a judge presiding over a court case on the VW scandal, could justify a court decision by appealing to the common good." And we suggested that "she would never confuse it with reputation".

We can now explain this appeal to intuition on a conceptual level by examining such a thought experiment in a bit more detail. If the judge had to make a judgment regarding VW's public value, she would proceed as follows.

\section{Dominant Logic}

From the judge's individual perspective, she would care more about an organization's impact-the contribution it makes to the public - than about the organization being recognized by the public. In other words, the judge would care more about what people experience because of the organization, than about how they experience the organization as such. From the judge's individual perspective, these are fundamentally different ideas, so that one can expect the evaluation results to be quite different. Nevertheless, if the judge would try to empirically verify her assumptions through aggregating people's perceptions, she would run into issues regarding the differentiation between contribution and recognition as described above.

\section{Basis of Evaluation}

In any case, the judge would demand and apply a holistic basis of evaluation, considering VW's value with regard to all social units concerned and society as a whole, as well as with regard to all basic values which, e.g., are not merely the instrumental "quality" and "utility" of cars, but include 
aspects such as the company's moral conduct, their legal/ political and social value, and the impact it has on people's overall life quality. As such, the judgement at which the judge would arrive regarding VW's public value, would weigh the positive contribution made through high-quality cars against the negative impact of VW's actions on life quality, moral misconduct, and illegal behavior. The negative would most likely, at least partially, be compensated for by the positive. This distinction illustrates the difference between a reputation-whichever way the construct is defined-and public value's holistic basis of evaluation.

\section{Conclusion}

To sum up, the judge would never confuse reputation and public value as to her, they have a fundamentally different logic, and most likely they also differ in their basis of evaluation. The judge would be concerned about VWs contribution, not its recognition, and she would be concerned about a holistic basis of evaluation considering all social collectives and all their basic values, as opposed to single components of such a basis. The former distinction would only become blurred when attempting empirical verification through aggregation of individual views. The latter distinction would only become blurred when applying a similar basis of evaluation.

\section{Implications}

Our study is a theoretical endeavor, which compares public value and organizational reputation based on literature in the respective fields, and which infers propositions about their relationship. The comparison and propositions provided above have several implications for theory and practice.

\section{Theoretical Implications and Further Research}

We started our enquiry postulating that, intuitively, public value and reputation seem to be fundamentally different concepts, while from a theoretical perspective they apparently share certain similarities.

Above all, our enquiry helps to answer the question regarding the similarities and differences of the two constructs. In general, the construct's structural similarities could be responsible for most of the confusion. Nevertheless, they differ fundamentally regarding the basis of evaluation and dominant logic. This delineation benefits both areas of research, as well as potential future research on their relationship as follows.

First, given the structural similarities, it is likely that theoretical considerations and empirical findings in reputation research can be transferred to public value research, and vice versa, and in that each research area will benefit independently. Beyond that, our propositions indicate that much conceptual and empirical research can be done regarding their relationship. This offers opportunities for new, integrated research programs, integrative theory building, and empirical endeavors. Conceptually, one can elaborate on how public value and reputation influence each other, on common antecedents or common effects. Empirically, our propositions and potential further ones provide a lot of room for empirical validation. Not only the basis of evaluation and the objects of evaluation, but also the cultural contexts and methods applied, imply various degrees of freedom regarding hypotheses and research designs. A sensible first step could be an in-depth case study of a particular event, analyzing and comparing public value and organizational reputation antecedents and consequences. Cases which might lend themselves well to such study are the Volkswagen diesel emission scandal or the introduction of end-to-end encryption by WhatsApp. Another approach would be to conduct large-scale quantitative studies across a number of organizations. This could answer the question whether a high reputation implies high public value, and vice versa. Further research could also enquire whether structural features of reputation in industries (e.g., reputation commons-King et al. 2002), which could be discovered empirically in the VW case (Bachmann 2017) also apply to public value.

Despite the similarities and relationships we could establish, for the reasons stated in Propositions 3 and 4, the constructs should not be confused, and more depth is required to delineate the constructs both conceptually and empirically. We have identified a thorough micro-foundation, and consequently the basis of evaluation and the dominant logic as promising starting points for such endeavors. Our study reflects the benefits of connecting the macro- and micro-level perspective of constructs like public value and reputation through a microfoundation in human psychology. We showed that a microfoundation of public value is transferrable to all constructs that involve human evaluation, and could in that way again not only highlight, but also sharpen the multi-dimensionality of the reputation construct. Future research could follow-up on this micro-foundation, and in that way attempt to provide more conceptual depth to reputation research. The same holds true for the process dynamics. While public value theory conceptualizes any change of public value as a synergetic process of self-organization, reputation research has been less explicit about a theory of change. Additionally, while public value theory already benefits from a micro-foundation, the challenging comparison also brings more depth to the public value construct. Our study shows that even though public value appears to be more sharply defined than the reputation construct, several open questions remain with respect to the distinction between individual application of the construct as a regulative idea, and collective quality of individual evaluations. Both constructs would benefit from a closer investigation into which frames of reference are exactly included or excluded in evaluations, both on the individual and on an aggregate level.

Moreover, the distinction between individual and collective perspectives highlights that both constructs need more 
clarity on how an "aggregate intersubjective" evaluation can be arrived at both conceptually and empirically. As long as there are no clear definitions, the distinction of the constructs on a macro level will stay blurred. Of course, for the reasons provided above, on a collective level some similarities will remain, but through a more comprehensive theory, as well as more sophisticated methods, one could perhaps distinguish further dimensionalities, e.g., with regard to conscious and unconscious perceptions and evaluations.

\section{Practical Implications}

Besides opening up avenues for future research, our study has implications for practice. The first and foremost message to all practitioners must be that although reputation and public value have structural similarities, they are fundamentally different concepts that have to be managed separately.

There are similarities as both constructs regard evaluations of the organization by a collective, i.e., through an outside-in perspective, to be beyond the organization's direct control. Further, they are of high strategic relevance, because they are linked to an organization's performance and potential for survival. Outside-in perspectives, as feedback drawn from the collectives that an organization interacts with, are key to any organization's long-term success, since such perspectives constitute a source of legitimization, as well as of motivation for individuals and collectives, be they employees, customers, other stakeholders, or society as a whole, to act for and interact with the organization. In this respect, reputation and public value are of similar importance. Moreover, when empirically assessing collective perspectives, the structural similarities do lead to challenges in delineating public value and a "reputation for public value." Practitioners, like researchers, should be aware of these challenges and work together to make sense of them and resolve them going forward.

Nevertheless, public value and reputation refer to fundamentally different concepts; hence, managers need primarily to consider both independently of each other. Only then can they make inferences about their relationship and potential common influences and effects. This becomes clear when considering the delineations provided earlier.

There are several reasons why managers should care about this: First, public value offers a resource for the individual to derive meaning, purpose, and consequently also motivation (Meynhardt et al. 2018a), which of course can be transformed into economic productivity (Meynhardt et al. 2018b). Second, reflecting on others' basic needs can eventually result in an increased ability to serve these needs. And third, the simple fact that any positive or negative contribution to a collective could at some point be recognized by the collective shows that considering public value provides a means to foresee and manage critical chances and risks concerning the organization, which might also have reputational consequences.
Of course, managers can legitimately challenge the last point. As long as others do not recognize the organization's contributions, the value created or destroyed will not affect the value of the organization as such. This highlights the elaborated similarities between public value and a reputation for public value on an empirically aggregated level. Value creating actions of an organization need to be communicated proactively to turn into further positive effects for the organization. Value destroying actions of an organization need, from a managerial perspective, to be avoided, or at least considered in a communication strategy. For value destroying actions, of course stakeholders have the responsibility to demand transparency, or to set incentives to avoid them. The fact that at some point "the public could recognize" is even more striking in times when information flows increase and data protection becomes challenging.

\section{Conclusion}

Public value and reputation both relate to an important concept of our times, namely the value an organization has for a collective. Through an in-depth comparison of the two constructs, we could elaborate on their similarities and highlight the major differences between them. Given that the concepts stem from different research traditions and, at first sight, appear to describe distinct phenomena, it was striking to see that - on a structural macro-level-important similarities exist. Both constructs are strategically very relevant for organizations, while both are social approval assets with an external locus of control. Both have a relational axiological structure and accordingly a predominantly relative measurement on an ordinal scale. Further, both concepts share synergetic process dynamics, which are more explicitly spelled out in the public value literature.

However, public value and reputation differ along two important dimensions when taking the individual micro level into account. Public value applies a holistic basis of evaluation, while the reputation construct is more adaptive. Moreover, public value follows a logic of contribution to the collective, while reputation is about recognition by the collective. The comparison of these constructs opens up new perspectives, relates different discourses in new ways, and highlights their mutual, yet independent importance for managerial practice. Reputation and public value both represent important ideas and order parameters in our individual and intersubjective realities, which gain utmost importance in an era of increasing transparency and interconnectedness.

Acknowledgements We would like to thank the anonymous reviewers and the editor for their helpful comments on earlier versions of this article.

\section{Appendix}

See Table 1 and Fig. 1. 
Table 1 Comparing public value and reputation

\begin{tabular}{lll}
\hline Dimension & Public value & Reputation \\
\hline Commonalities & & \\
Strategic relevance & Yes & Yes \\
Locus of control & External & External \\
Measurement unit/baseline & Predominantly relative & Predominantly relative \\
Process dynamics & Explicit description & Implicit/transferable description \\
Axiological nature & Relational & Relational \\
Differences & & \\
Basis of evaluation & Holistic & Adaptive (specific or holistic) \\
Dominant logic & Contribution & Recognition \\
\hline
\end{tabular}

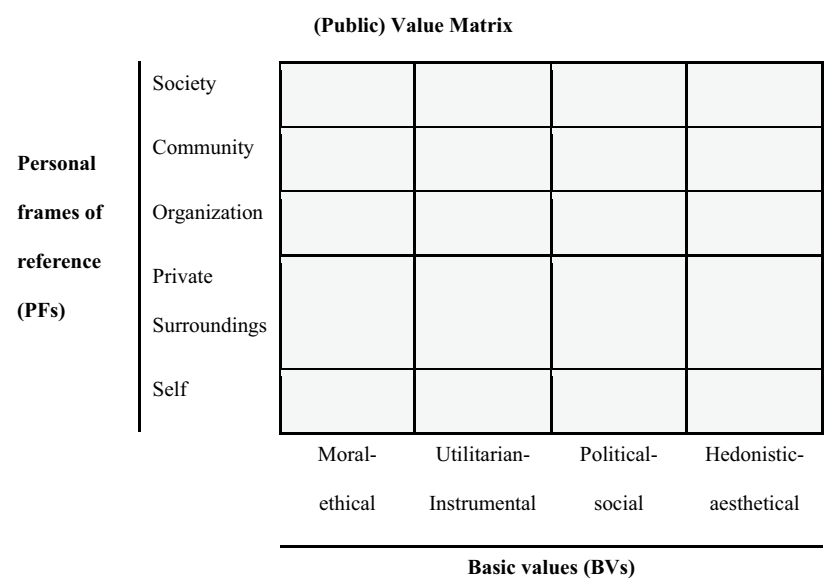

Fig. 1 (Public) value matrix

\section{References}

Aguinis, H., and A. Glavas. 2012. What we know and don't know about corporate social responsibility a review and research agenda. Journal of Management 38 (4): 932-968.

Bachmann, R., Ehrlich, G. and Ruzic, D. (2017), Firms and collective reputation: The Volkswagen emissions scandal as a case study. CEPR discussion paper no. 12504.

Barnett, M.L., J.M. Jermier, and B.A. Lafferty. 2006. Corporate reputation: The definitional landscape. Corporate Reputation Review 9 (1): 26-38.

Barney, J., and T. Felin. 2013. What are microfoundations? Academy of Management Perspectives 27 (2): 138-155.

Barnett, M.L., and T.G. Pollock. 2012. Charting the landscape of corporate reputation research. In The Oxford handbook of corporate reputation, ed. T.G. Pollock and M.L. Barnett, 1-15. Oxford: Oxford University Press.

Berndt, T., Bilolo, C. and Meynhardt, T. (2015) Investing in legitimacy: A performance analysis of public value stock portfolios. Paper presented at ACRN social and sustainable finance and impact investing conference; April, Oxford, UK.

Benjamin, B.A., and J.M. Podolny. 1999. Status, quality, and social order in the California Wine industry. Administrative Science Quarterly 44 (3): 563-589.

Bilolo, C. 2018. Legitimacy, public value, \& capital allocation. London: Routledge.
Boyd, B.K., D.D. Bergh, and D.J. Ketchen Jr. 2010. Reconsidering the reputation-performance relationship: A resource-based view. Journal of Management 36 (3): 588-609.

Brooks, M.E., S. Highhouse, S.S. Russell, and D.C. Mohr. 2003. Familiarity, ambivalence, and firm reputation: Is corporate fame a double-edged sword? Journal of Applied Psychology 88 (5): 904-914.

Bryson, J.M., B.C. Crosby, and L. Bloomberg. 2014. Public value governance: Moving beyond traditional public administration and the new public management. Public Administration Review 74 (4): 445-456.

Bryson, J.M., B.C. Crosby, and L. Bloomberg. 2015. Public value and public administration. Washington, DC: Georgetown University Press.

Cable, D.M., and M.E. Graham. 2000. The determinants of job seekers' reputation perceptions. Journal of Organizational Behavior 21 (8): 929-947.

Campbell, J.L. 2007. Why would corporations behave in socially responsible ways? An institutional theory of corporate social responsibility. The Academy of Management Review 32 (3): 946-967.

Carroll, A.B. 1991. The pyramid of corporate social responsibility: Toward the moral management of organizational stakeholders. Business Horizons 34 (4): 39-48.

Carroll, A.B., and K.M. Shabana. 2010. The business case for corporate social responsibility: A review of concepts, research and practice. International Journal of Management Reviews 12 (1): 85-105.

Chun, R. 2005. Corporate reputation: Meaning and measurement. International Journal of Management Reviews 7 (2): 91-109.

Davies, G., R. Chun, R.V. da Silva, and S. Roper. 2001. The personification metaphor as a measurement approach for corporate reputation. Corporate Reputation Review 4: 113-127.

Dowling, G.R. 2001. Creating corporate reputations. Oxford: Oxford University Press.

Drucker, P.F. 1973. Management: Tasks, responsibilities, practices. New York: Harper \& Row.

Drucker, P.F. 1992. The new society of organizations. Harvard Business Review 70 (5): 95-105.

Ebeling, W., and R. Feistel. 1994. Chaos und Kosmos. Prinzipien der Evolution. Heidelberg: Spektrum Akademischer.

Epstein, S. 1989. Values from the perspective of cognitive-experiential self-theory. In Social and moral values: Individual and societal perspectives, 8th ed, ed. N.E. Eisenberg, J.E. Reykowski, and E.E. Staub, 3-22. Hillsdale: Lawrence Erlbaum Associates.

Epstein, S. 2003. Cognitive-experiential self-theory of personality. In Handbook of psychology: Handbook of psychology. Personality and social psychology, vol. 5, ed. T. Millon, M.L. Lerner, and I.B. Weiner, 159-184. New York: Wiley. 
Fischer, E., and R. Reuber. 2007. The, the bad, and the unfamiliar: The challenges of reputation formation facing new firms. Entrepreneurship Theory and Practice 31 (1): 53-75.

Fiske, S.T. 1995. Social cognition. In Advanced social psychology, ed. A. Tesser, 149-193. New York: McGraw-Hill.

Fiske, S.T., and S.E. Taylor. 1991. Social cognition, 2nd ed. New York: McGraw-Hill.

Fombrun, C.J. 1996. Reputation: Realizing value from the corporate image. Boston: Harvard Business School Press.

Fombrun, C. 2012. Corporate reputation: Definitions, antecedents, consequences. The Oxford handbook of corporate reputation, 94-113. Oxford: Oxford University Press.

Fombrun, C.J., and M. Shanley. 1990. What's in a name? Reputation building and corporate strategy. Academy of Management Journal 33 (2): 233-258.

Fombrun, C.J., and C.B.M. van Riel. 1997. The reputational landscape. Corporate Reputation Review 1 (2): 5-13.

Garriga, E., and D. Melé. 2004. Corporate social responsibility theories: Mapping the territory. Journal of Business Ethics 53 (1-2): 51-71.

Haken, H. 1977. Synergetics: Nonequilibrium phase transition and self-organization in physics, chemistry and biology. Berlin: Springer.

Haken, H. 1984. Can synergetics be of use to management theory? Springer Series in Synergetics 26: 33-41.

Heyde, J.E. 1926. Wert: eine philosophische Grundlegung. Erfurt: Stenger.

Iwin, A.A. 1975. Grundlagen der Logik von Wertungen. Berlin: Akademie-Verlag.

Kearney, C., and T. Meynhardt. 2016. Directing corporate entrepreneurship strategy in the public sector to public value: Antecedents, components, and outcomes. International Public Management Journal 19 (4): 543-572.

Kegan, R. 1982. The evolving self: Problem and process in human development. Harvard: Harvard University Press.

Kegan, R. 1995. In over our heads: The mental demands of modern life. Harvard: Harvard University Press.

King, A.A., M.J. Lenox, and M. Barnett. 2002. Strategic responses to the reputation commons problem. In Organizations, policy, and the natural environment: Institutional and strategic perspectives, ed. A.J. Hoffman and M.J. Ventresca, 393-406. Stanford: Stanford University Press.

Kohlberg, L. 1984. The psychology of moral development: The nature and validity of moral stages/Lawrence Kohlberg, essays on moral development, vol. 2. San Francisco: Harper \& Row.

Kraatz, M.S., and E.G. Love. 2006. Studying the dynamics of reputation: A framework for research on the reputational consequences of corporate actions. Research Methodology in Strategy and Management 3: 343-383.

Lange, D., P.M. Lee, and Y. Dai. 2011. Organizational reputation: A review. Journal of Management 37 (1): 153-184.

Love, E.G., and M.S. Kraatz. 2009. Character, conformity, or the bottom line? How and why downsizing affected corporate reputation. Academy of Management Journal 52 (2): 314-335.

Meynhardt, T. 2008. Public Value - oder: was heißt Wertschöpfung zum Gemeinwohl? dms - der moderne staat 2: 73-91.

Meynhardt, T. 2009. Public value inside: What is public value creation? International Journal of Public Administration 32 (3-4): 192-219.

Meynhardt, T. 2015. Public Value: Turning a Conceptual Framework into a Scorecard. In Public value and public administration, ed. J.M. Bryson, B.C. Crosby, and L. Bloomberg, 147-169. Washington, DC: Georgetown University Press.

Meynhardt, T. 2016. Public value: The contribution of organizations and companies to the common good. In Responsible entrepreneurship: Business and society: Bridging the gap, ed. Bertelsmann Stiftung, 25-35. Gütersloh: Bertelsmann Stiftung.

Meynhardt, T. 2019. Public value: value creation in the eyes of society. In Public Value - Deepening, Enriching, and Broadening the Theory and Practice, ed. A. Lindgreen, N. Koenig-Lewis, M. Kitchener, J. Brewer, M. Moore, and T. Meynhardt, 5-22. London: Routledge.

Meynhardt, T., and A. Bäro. 2019. Public value reporting: adding value to (non-)financial reporting. In Public Value - Deepening, Enriching, and Broadening the Theory and Practice, ed. A. Lindgreen, N. Koenig-Lewis, M. Kitchener, J. Brewer, M. Moore, and T. Meynhardt, 87-108. London: Routledge.

Meynhardt, T., and S. Bartholomes. 2011. (De)composing public value: in search of basic dimensions and common ground. International Public Management Journal 14 (3): 284-308.

Meynhardt, T., S.A. Brieger, P. Strathoff, S. Anderer, A. Bäro, C. Hermann, and P. Gomez. 2017. Public value performance: What does it mean to create value in the public sector? In Public sector management in a globalized world, ed. R.C. Andeßner, D. Greiling, and R. Vogel, 135-160. Wiesbaden: Springer Fachmedien.

Meynhardt, T., S.A. Brieger, and C. Hermann. 2018a. Organizational public value and employee life satisfaction: the mediating roles of work engagement and organizational citizenship behavior. The International Journal of Human Resource Management. https:// doi.org/10.1080/09585192.2017.1416653.

Meynhardt, T., J.D. Chandler, and P. Strathoff. 2016. Systemic principles of value co-creation: Synergetics of value and service ecosystems. Journal of Business Research 69 (8): 2981-2989.

Meynhardt, T., and A. Fröhlich. 2019. More value awareness for more (public) value: Recognizing how and for who value truly is created. In Public Value - Deepening, Enriching, and Broadening the Theory and Practice, ed. A. Lindgreen, N. Koenig-Lewis, M. Kitchener, J. Brewer, M. Moore, and T. Meynhardt, 23-39. London: Routledge.

Meynhardt, T., and P. Gomez. 2014. Public value: Gesellschaftliche Wertschöpfung als unternehmerische Pflicht. In Managementperspektiven für die Zivilgesellschaft des 21. Jahrhunderts, ed. C. von Müller and C.-P. Zinth, 17-26. Wiesbaden: Springer Fachmedien.

Meynhardt, T., and P. Gomez. 2016. Building blocks for alternative four-dimensional pyramids of corporate social responsibilities. Business \& Society. 58: 404-438. https://doi.org/10.1177/00076 50316650444.

Meynhardt, T., P. Neumann, and F. Christandl. 2018b. Sinn für das Gemeinwohl. Harvard Business Manager 3: 66-71.

Meynhardt, T., P. Strathoff, L. Beringer, and S. Bernard. 2015. FC Bayern Munich: Creating public value between local embeddedness and global growth. Cranfield: The Case Centre.

Meynhardt, T., and C. von Müller. 2013. Wir wollen Werte schaffen für die Gesellschaft: Der Public Value im Spannungsfeld zwischen Aktienwert und Gemeinwohl Eine Fallstudie am Beispiel der Deutsche Börse AG. ZögU: Zeitschrift für öffentliche und gemeinwirtschaftliche Unternehmen 36 (2-3): 119-149.

Moore, M.H. 1995. Creating public value: Strategic management in government. Cambridge: Harvard University Press.

Pfarrer, M.D., T.G. Pollock, and V.P. Rindova. 2010. A tale of two assets: The effects of firm reputation and celebrity on earnings surprises and investors' reactions. Academy of Management Journal 53 (5): 1131-1152.

Podnar, K., and U. Golob. 2017. The quest for the corporate reputation definition: Lessons from the interconnection model of identity, image, and reputation. Corporate Reputation Review 20 (3-4): 186-192.

Rescher, N. 1969. Introduction to value theory. Englewood Cliffs: Prentice-Hall. 
Rhee, M., and M.E. Valdez. 2009. Contextual factors surrounding reputation damage with potential implications for reputation repair. The Academy of Management Review 34 (1): 146-168.

Rindova, V.P., I.O. Williamson, A.P. Petkova, and J.M. Sever. 2005. Being good or being known: An empirical examination of the dimensions, antecedents, and consequences of organizational reputation. The Academy of Management Journal 48 (8): 1033-1049.

Roberts, P.W., and G.R. Dowling. 2002. Corporate reputation and sustained superior financial performance. Strategic Management Journal 23 (12): 1077-1093.

Rotter, J. 1954. Social learning and clinical psychology. New York: Prentice-Hall.

Rotter, J. 1966. Generalized expectancies of internal versus external control of reinforcements. Psychological Monographs 80: 1-28.

Schutz, A., and T. Luckmann. 1973. The structures of the life-world. Evanston: Northwestern University Press.

Schutz, A. 1974. Der sinnhafte Aufbau der sozialen Welt: Eine Einleitung in die verstehende Soziologie. Frankfurt am Main: Suhrkamp.

Schwartz, M.S., and A.B. Carroll. 2008. Integrating and unifying competing and complementary frameworks: The search for a common core in the business and society field. Business \& Society 47 (2): 148-186.

Shamsie, J. 2003. The context of dominance: An industry-driven framework for exploiting reputation. Strategic Management Journal 24 (3): 199-215.

Shapiro, C. 1983. Premiums for high quality products as returns to reputations. The Quarterly Journal of Economics 98 (4): 659-679.

Strathoff, P. 2015. The VBA model and public value: Filling the value gap. Business \& Professional Ethics Journal 33 (4): 297-319.

Turban, D.B., C.-M. Lau, H.-Y. Ngo, I.H.S. Chow, and S.X. Si. 2001. Organizational attractiveness of firms in the People's Republic of China: A person-organization fit perspective. Journal of Applied Psychology 86 (2): 194-206.

Walker, K. 2010. A systematic review of the corporate reputation literature: Definition, measurement, and theory. Corporate Reputation Review 12 (4): 357-387.

Zajonc, R.B. 1968. Attitudinal effects of mere exposure. Journal of Personality and Social Psychology, Monograph Supplement 9 (2): 1-27.

Publisher's Note Springer Nature remains neutral with regard to jurisdictional claims in published maps and institutional affiliations.
Timo Meynhardt is Professor and Chair of the Dr. Arend Oetker Chair of Business Psychology and Leadership at HHL Leipzig Graduate School of Management, and Managing Director of the Center for Leadership and Values in Society at the University of St. Gallen. His research focuses on public value as a contribution to the common good (Gemeinwohl) - both in private and public sector.

Pepe Strathoff is a Fellow at the Center for Leadership and Values in Society at the University of St. Gallen, Switzerland. His doctoral thesis "Strategic Perspectives on Public Value" deals with public value questions related to strategic management. He was an Innovations in Goverment Program Fellow at Harvard Kennedy School January-December 2015 and holds an MSc in International Political Economy from the London School of Economics and Political Science.

Andreas Fröhlich received his doctorate at HHL Leipzig Graduate School of Management. His research focuses on the combination of psychological and business-related topics, and in particular public value (Gemeinwohl), value awareness, value creation, and the relations among these concepts. He holds an MA in Strategy and International Management from University of St. Gallen, a BSc in Physics from Vienna University of Technology, and a BSc in Business Administration from Vienna University of Economics and Business.

Steven A. Brieger is Lecturer (Assistant Professor) in International Business at the University of Sussex Business School, University of Sussex, United Kingdom. He is also Research Fellow at the Center for Leadership and Values in Society at the University of St. Gallen, Switzerland. His research interests are situated in the areas of corporate responsibility, social entrepreneurship, political economy, and institutions. He has published in journals such as Journal of Business Ethics, Environment and Behavior, The International Human Resource Management Journal, and Small Business Economics. 